\title{
Outcomes of Laparoscopic Versus Open Left Lateral Sectionectomy; Single Center Experience; A Initiative to Be the Ground for Evidence
}

\author{
YoungRok Choi, M.D., Yoo-Seok Yoon, M.D., Ph.D. \\ Department of Surgery, Seoul National University Bundang Hospital, Seongnam, Korea
}

\author{
Corresponding author \\ Yoo-Seok Yoon \\ Department of Surgery, Seoul National University Bundang Hospital, 82, Gumi-ro 173, Bundang-gu, Seongnam 13620, Korea \\ Tel: +82-31-787-7099, Fax: +82-31-787-4078, E-mail: yoonys@snubh.org
}

This is an Open Access article distributed under the terms of the Creative Commons Attribution Non-Commercial License (http:// creativecommons.org/licenses/by-nc/4.0/) which permits unrestricted non-commercial use, distribution, and reproduction in any medium, provided the original work is properly cited.
Copyright (C) 2017 The Journal of Minimally Invasive Surgery. All rights reserved.
Since the first international consensus conference in 2008, ${ }^{1}$ laparoscopic liver resection (LLR) has been rapidly disseminated. With improvement of surgical technique and development of laparoscopic device, indications have expanded from minor liver resection to more complicated cases, including major liver resection and living donor hepatectomy. ${ }^{2}$ Advantages of LLR include less blood loss, smaller incisions, less abdominal wall complications, decreased postoperative morbidity, and shorter length of stay compared to open liver resection. With well-documented these advantages, laparoscopic left lateral sectionectomy and minor liver resection are now considered as a standard procedure worldwide. ${ }^{3}$ Along with this situation, there has been an exponential growth in the number of LLR in Korea. In Korean national survey in 2012, left lateral sectionectomy accounted for approximately $30 \%$ of all laparoscopic liver resections. ${ }^{4}$

This study compared the outcomes of laparoscopic and open left lateral sectionectomy based on retrospective analysis of a single-center experience. Previous studies reported that the laparoscopic approach was associated with a shorter length of hospital stay irrespective of the indication, a lower transfusion rate and earlier recovery in patients with benign condition or primary malignancy, even in cirrhotic patients. ${ }^{5-7}$ This study has the inherited limitations of the retrospective study with small number of patients. The selection criteria for laparo- scopic and open surgery were not presented clearly. The surgical and oncologic outcomes for various diseases were mixed. Nevertheless, authors presented valuable data with a specific focus on left lateral sectionectomy of a Korean institution that early adopted this operative procedure. The initial time of the study period (from 2008 to 2015) was when there was still controversy about the application of LLR, especially for malignancy in Korea. The results of this study reconfirmed the advantage of laparoscopic left lateral sectionectomy in that it was associated with less bleeding and shorter hospital stay compared to open surgery. Moreover, the authors pointed out the necessity of large-scale prospective studies or national registry to overcome the limited evidence based on smallscale single center research. This study is meaningful as a preliminary study which will be the basis for further multicenter collaborative studies. We hope that a collection of small retrospective studies like this study will be the ground to develop evidence for generalization of laparoscopic left lateral sectionectomy.

\section{REFERENCES}

1) Buell JF, Cherqui D, Geller DA, et al. The international position on laparoscopic liver surgery: The Louisville Statement, 2008. Ann Surg 2009;250:825-830. 
2) Wakabayashi G, Cherqui D, Geller DA, et al. Recommendations for laparoscopic liver resection: a report from the second international consensus conference held in Morioka. Ann Surg 2015;261:619-629.

3) Choi YR, Lee $\mathrm{K}-\mathrm{W}$. From venture to evidence in laparoscopic liver resection. Ann Laparosc Endosc Surg 2016;1:34.

4) Park JS, Han HS, Hwang DW, et al. Current status of laparoscopic liver resection in Korea. J Korean Med Sci 2012;27:767-771.

5) Aldrighetti L, Pulitano C, Catena M, et al. A prospective evalua- tion of laparoscopic versus open left lateral hepatic sectionectomy. J Gastrointest Surg 2008;12:457-462.

6) Goutte N, Bendersky N, Barbier L, Falissard B, Farges O. Laparoscopic left lateral sectionectomy: a population-based study. HPB (Oxford) 2017;19:118-125.

7) Im C, Cho JY, Han HS, et al. Laparoscopic left lateral sectionectomy in patients with histologically confirmed cirrhosis. Surg Oncol 2016;25:132-138. 